\title{
EHMTI-0215. The impact of post-herpetic neuralgia on patients with chronic primary headaches
}

\author{
A Avetisyan ${ }^{1 *}$, AS Harutyunyan², HR Vekilyan', AH Karapetyan', EM Gevorgyan', HM Manvelyan \\ From 4th European Headache and Migraine Trust International Congress: EHMTIC 2014 \\ Copenhagen, Denmark. 18-21 September 2014
}

\section{Introduction}

Increasing number of patients with post-herpetic neuralgia (PHN) leads to clinical observation of the fact that it worsening the condition of patients with other chronic pain syndromes such as migraine and tension-type headache (TTH).

\section{Aims}

The aim of this study was assessment of cephalgic pain severity and quality of life (QoL) in patients with primary headaches in comparison with those who additionally suffers of PHN.

\section{Methods}

12 patients with PHN and comorbid migraine and TTH (3 and 9, respectively) and 14 patients with migraine and TTH only (4 and 10) as controls were assessed for headache pain severity by visual analog scale (VAS) and QoL by short form (SF-36) screening tools.

\section{Results}

Patients with PHN had worse results of headache pain intensity and QoL vs patients of control group. Headache pain severity in PHN group was 7-8 vs 5-6 in control group, and QoL scoring was lower in PHN group vs control.

\section{Conclusion}

PHN as the reason of central sensitization leads to further increase of the other chronic pain syndromes, such as primary headaches, elevate the cephalgic pain and decrease the QoL.

${ }^{1}$ Neurology, Yerevan State Medical University after M.Heratsi, Yerevan, Armenia

Full list of author information is available at the end of the article
No conflict of interest.

\section{Authors' details}

${ }^{1}$ Neurology, Yerevan State Medical University after M.Heratsi, Yerevan, Armenia. ${ }^{2}$ Neurology, 2nd hospital, Yerevan, Armenia.

Published: 18 September 2014

doi:10.1186/1129-2377-15-S1-D28

Cite this article as: Avetisyan et al: EHMTI-0215. The impact of postherpetic neuralgia on patients with chronic primary headaches. The Journal of Headache and Pain 2014 15(Suppl 1):D28.

\section{SpringerOpen ${ }^{\circ}$}

C 2014 Avetisyan et al; licensee Springer. This is an Open Access article distributed under the terms of the Creative Commons Attribution License (http://creativecommons.org/licenses/by/2.0), which permits unrestricted use, distribution, and reproduction in any medium, provided the original work is properly cited.
Submit your manuscript to a SpringerOpen ${ }^{\circ}$ journal and benefit from:

- Convenient online submission

- Rigorous peer review

- Immediate publication on acceptance

- Open access: articles freely available online

- High visibility within the field

- Retaining the copyright to your article

Submit your next manuscript at $>$ springeropen.com 